\title{
Tingkat Keberhasilan Penetasan Telur Penyu Lekang (Lepidochelys olivacea) pada Sarang Semi Alami di Pantai Boom Banyuwangi Periode Tahun 2018
}

\section{Hatching Percentage of Olive Ridley Turtle (Lepidochelys olivacea) Eggs in Semi-Natural Nest at Boom Beach Benyuwangi Within Period 2018}

\author{
Ayu Riza Umama ${ }^{1 *}$, Tjuk Imam Restiadi², Ragil Angga Prastiya ${ }^{2}$, Erma Safitri ${ }^{2}$, \\ Amung Logam Saputro ${ }^{3}$, Aditya Yudhana ${ }^{4}$, Wiyanto Haditanojo ${ }^{5}$ \\ ${ }^{1}$ Pendidikan Profesi Dokter Hewan, ${ }^{2}$ Departemen Reproduksi Veteriner, ${ }^{3}$ Departemen Klinik Veteriner, \\ ${ }^{4}$ Departemen Parasitologi Veteriner, ${ }^{5}$ Banyuwangi Sea Turtle Foundation, \\ Fakultas Kedokteran Hewan, Universitas Airlangga, \\ Kampus C Mulyorejo, Surabaya, Jawa Timur, Indonesia, 60115 \\ *Corresponding author: arizaumama@gmail.com
}

\begin{abstract}
Abstrak
Penelitian ini bertujuan mengetahui persentase keberhasilan penetasan telur penyu lekang (Lepidoehelys olivacea) pada sarang semi alami Banyuwangi sea Turtle Foundation (BSTF) di Pantai Boom Banyuwangi. Data diperoleh dari observasi dan rekap data milik BSTF. Persentase keberhasilan penetasan diperoleh dari total telur penyu lekang selama periode bertelur tahun 2018. Persentase penetas an telur penyu lekang pada sarang semi alami BSTF periode tahun 2018 adalah 75\%. Total telur penyu yang diinkubasikan adalah 4495 butir, total telur yang menetas adalah 3392 butir, dan jumlah telur yang gagal menetas adalah 1103 butir.
\end{abstract}

Kata kunci: Pantai Boom, Lepidochelys olivacea, sarang semi alami, persentase penetasan

\begin{abstract}
This study aimed to determine hatching success percentage of Olive Ridley (Lepidochelys olivacea) turtle eggs in semi-natural nest which managed by Banyuwangi Sea Turtle Foundation (BSTF) at Boom Beach, Banyuwangi. Data obtained by observation and recording activity from BSTF. Percentage of hatching success was obtained from the total eggs of Olive Ridley during the nesting period in 2018. The percentage hatching rate of Olive Ridley turtle in semi-natural nests of BSTF during period 2018 wast $75 \%$. A total of 4495 eggs were incubated within semi-natural nest, obtained 3392 eegs were successfully hatch and 1103 unhatched eegs were found during this study.
\end{abstract}

Key words: Boom Beach, Lepidochelys olivacea, semi-natural nest, hatching percentage

\section{PENDAHULUAN}

Enam dari tujuh spesies penyu dunia dapat ditemukan di perairan Indonesia. Empat diantaranya yaitu penyu hijau, penyu belimbing, penyu sisik dan penyu lekang ditemukan bertelur di Pantai Ngagelan Taman Nasional Alas Purwo, Kabupaten Banyuwangi dengan jumlah telur didominasi oleh penyu lekang (Lepidochelys olivacea) (Dermawan dkk., 2009). Tempat lain yang juga dijadikan tempat bertelur penyu lekang yaitu Pantai Boom Banyuwangi yang berada dekat dengan tengah kota dan rawan terhadap gangguan (Samosir dkk., 2018).

Maulany et al. (2012) menyebutkan bahwa predator merupakan salah satu gangguan terhadap telur di sarang alami, selain itu rendahnya keberhasilan penetasan (O'Connor et al., 2017; Behera et al., 2014) juga dapat mempengaruhi populasi penyu dilautan. Akibat penurunan yang signifikan pada tahun 2015 penyu lekang masuk dalam Red List oleh International Union for 
Conservation of Nature (IUCN) dengan kategori Vulnerable yang artinya penyu beresiko mengalami kepunahan di alam liar pada masa yang akan datang (Mortimer \& Donnelly 2008).

Usaha yang dapat dilakukan untuk meningkatkan penetasan dan melindungi telur penyu adalah dengan melakukan konservasi melalui pemindahan telur ke sarang semi alami (Karnan, 2008). Banyuwangi Sea Turtle Foundation (BSTF) merupakan organisasi yang melakukan relokasi telur penyu ke sarang semi alami di Pantai Boom Banyuwangi sejak tahun 2011. Tahun 2016 dan 2017 BSTF mengalami penurunan keberhasialan penetasan telur Penyu Lekang, namun belum ada data ilmiah mengenai tingkat keberhasilan penetasan telur penyu lekang pada sarang semi alami BSTF sehingga sulit untuk melakukan perbandingan data dari tahun ke tahun.

Berdasarkan hal tersebut peneliti ingin mengetahui persentase keberhasilan penetasan telur penyu lekang pada sarang semi alami BSTF sehingga bisa dijadikan sumber data ilmiah dan data pembanding keberhasilan tahun berikutnya agar dapat memperkecil resiko penetasan. Aspek yang diamati adalah jumlah telur pada periode bertelur tahun 2018, jumlah total telur yang menetas, jumlah telur yang gagal menetas, serta data pendukung yaitu suhu sarang, kelembaban, dan $\mathrm{pH}$ pasir sarang.

\section{METODE PENELITIAN}

Penelitian dilaksanakan di sarang semi alami milik BSTF di Pantai Boom Banyuwangi. Penelitian dilakukan selama periode bertelur penyu lekang tahun 2018. Aspek yang diamati yaitu jumlah total telur, jumlah telur menetas, dan jumlah telur tidak menetas.

Sampel penelitian adalah semua telur penyu lekang yang diambil dari sarang alami di sepanjang Pantai Boom Banyuwangi dan dipindahkan ke sarang semi alami BSTF. Langkah penelitian yaitu observasi induk penyu lekang, untuk memastikan spesies induk. Pengamatan induk bertelur kemudian pembongkaran sarang alami ketika induk telah meninggalkan pantai. Pemindahan telur dari sarang alami dan perhitungan jumlah telur. Persiapan sarang semi alami, inkubasi telur pada sarang semi alami, dan pemantauan masa inkubasi. Selama masa inkubasi dilakukan pengambilan data suhu sarang, kelembaban sarang dan pengukuran $\mathrm{pH}$ pasir sarang. Kemudian dilakukan pengamatan keberhasilan penetasan dan pembongkaran sarang. Alat yang digunakan antara lain mini LCD digital Hygrometer Termometer untuk mengukur suhu dan kelembaban, Soil pH dan Moisture Tester untuk mengukur $\mathrm{pH}$ pasir sarang, glove, sekop untuk menggali pasir, pipa paralon untuk membantu penggalian pasir, ember plastik untuk memindahkan telur, alat tulis, dan kamera.

Penelitian ini menggunakan metode deskriptif. Data total jumlah telur, jumlah telur yang menetas, dan jumlah telur yang gagal menetas dihitung menggunakan rumus (Listiani dkk., 2015), sebagai berikut:

$\%$ Penetasan $=\underline{\text { Jumlah telur menetas }} \times 100 \%$ Jumlah total telur

\section{HASIL DAN PEMBAHASAN}

Persentase penetasan telur penyu lekang pada sarang semi alami BSTF dapat dilihat pada Tabel 1. Disajikan data jumlah total telur, jumlah telur yang menetas, jumlah telur yang gagal menetas, persentase penetasan per bulan, suhu, kelembaban, dan $\mathrm{pH}$ sarang.

Persentase keberhasilan menetas telur penyu lekang pada sarang semi alami adalah $75 \%$. Persentase penetasan pada bulan April sebesar 63\% dan pada bulan Mei 75\%. Persentase penetasan tertinggi terjadi pada bulan Juni dengan nilai $79 \%$, sedangkan pada bulan Juli yaitu $67 \%$. Persentase penetasan pada sarang semi alami di Pantai Boom banyuwangi lebih besar jika dibandingkan persentase penetasan di Pantai Samas Bantul pada sarang semi alami dengan nilai 60\% (Rofiah dkk., 2012). Penetasan dibeberapa pantai di Florida adalah 51,6\% untuk penyu tempayan, $50,0 \%$ untuk penyu hijau, dan $38,7 \%$ untuk penyu belimbing (Brost et al., 2015).

Periode bertelur penyu lekang di Pantai Boom Banyuwangi dimulai pada bulan April dan 
Tabel 1. Data penetasan telur penyu di sarang semi alami Pantai Boom Banyuwangi

\begin{tabular}{cccccccc}
\hline Bulan & $\begin{array}{c}\text { Jumlah telur } \\
\text { (butir) }\end{array}$ & $\begin{array}{c}\text { Menetas } \\
\text { (butir) }\end{array}$ & $\begin{array}{c}\text { Tidak menetas } \\
\text { (butir) }\end{array}$ & $\begin{array}{c}\text { Persentase } \\
\mathbf{\%}\end{array}$ & $\begin{array}{c}\text { Suhu } \\
\mathbf{0}^{\mathbf{C}}\end{array}$ & $\begin{array}{c}\text { Kelembaban } \\
\mathbf{\%}\end{array}$ & pH \\
\hline April & 560 & 354 & 206 & 63 & 29.8 & 72 & 3.9 \\
Mei & 1490 & 1121 & 369 & 75 & 28.7 & 65.6 & 4.9 \\
Juni & 2302 & 1821 & 481 & 79 & 29.9 & 75.3 & 5 \\
Juli & 143 & 96 & 47 & 67 & 29 & 80 & 5.4 \\
\hline & $\mathbf{4 4 9 5}$ & $\mathbf{3 3 9 2}$ & $\mathbf{1 1 0 3}$ & $\mathbf{7 5}$ & $\mathbf{2 9 - 3 2}$ & $\mathbf{6 7 - 8 0}$ & $\mathbf{3 . 8 - 6 . 7}$ \\
\hline
\end{tabular}

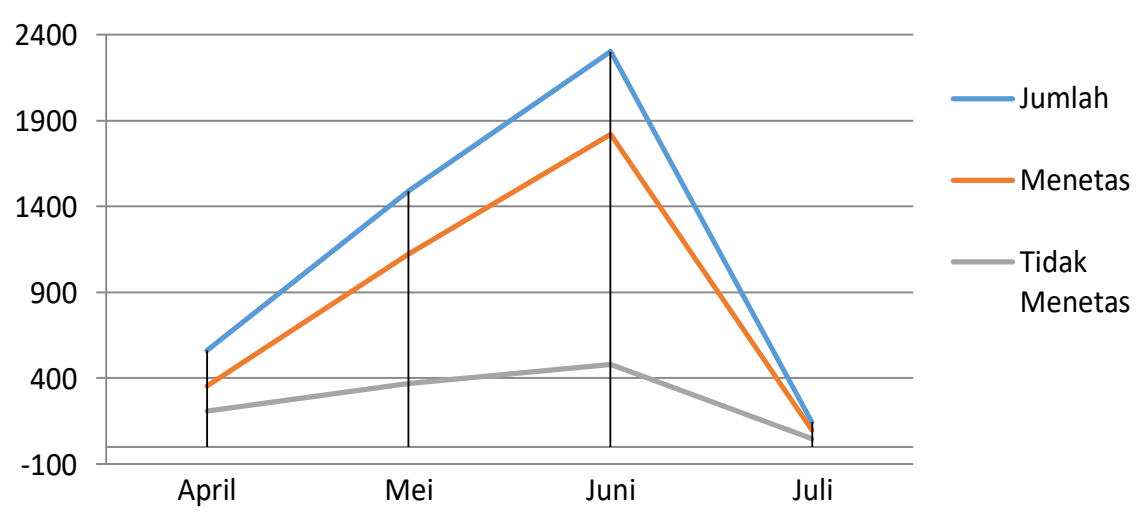

Gambar 1. Grafik penetasan telur tiap bulan di sarang semi alami Pantai Boom banyuwangi
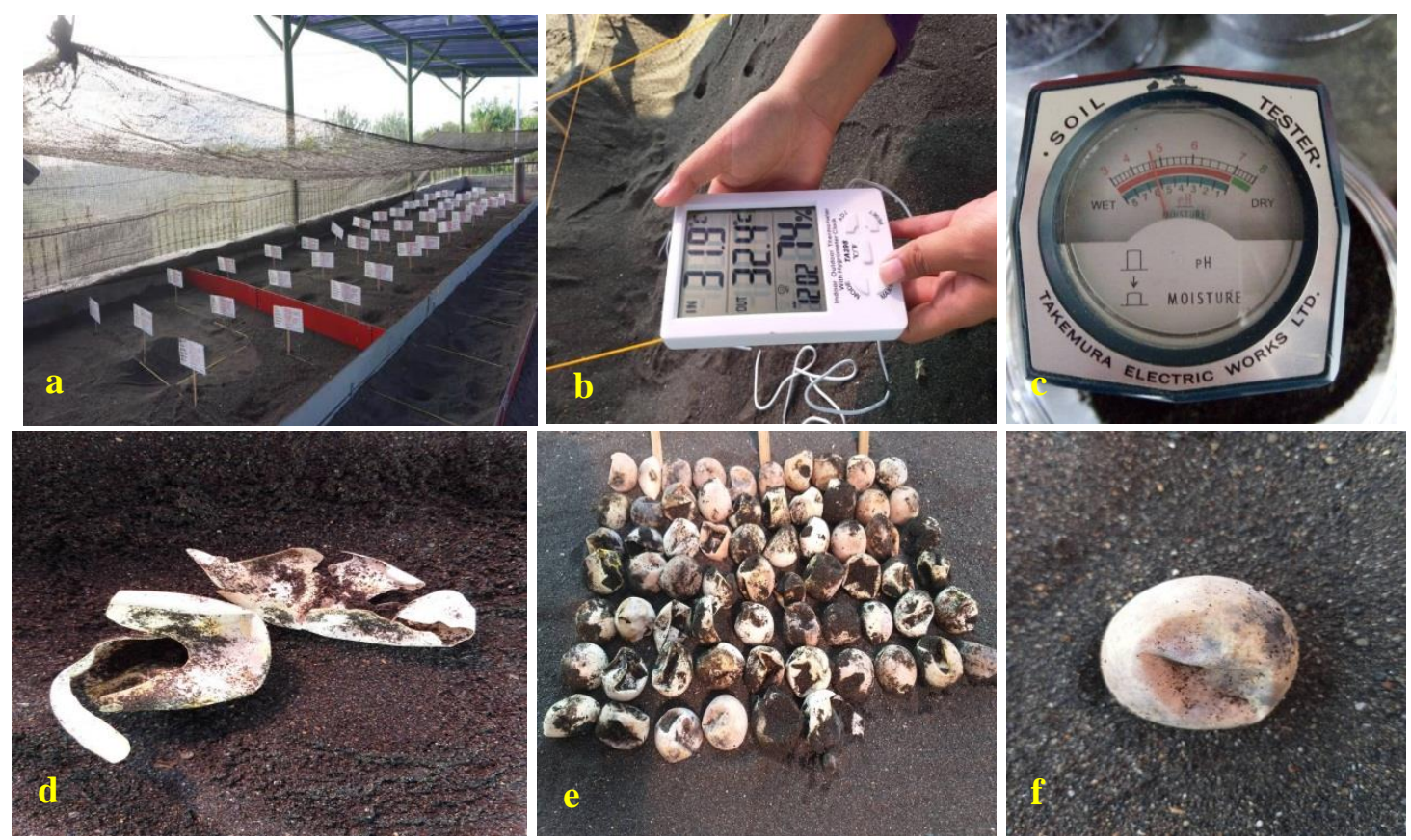

Gambar 2. Dokumentasi penelitian (a) sarang semi alami BSTF; (b) pengukuran suhu dan kelembaban sarang; (c) pengukuran $\mathrm{pH}$ sarang; (d) cangkang telur menetas; (e) telur gagal menetas; (f) telur gagal menetas cangkang keruh atau kekuningan

berakhir pada bulan Juli dengan puncak musim bertelur pada bulan Juni (Gambar 1). Hasil tersebut tidak jauh berbeda dengan pendapat Yustina dkk. (2004) bahwa musim bertelur penyu hijau di Pulau Jemur Kabupaten Rokan,
Riau terjadi pada bulan April, memuncak pada bulan Mei dan Juni, serta menurun pada bulan Juli. Masa bertelur penyu dapat berbeda berdasarkan jenis penyu dan lokasi bertelur. Menurut Sarahaizad et al., (2012) penyu bertelur 
ketika keadaan laut berombak dan air laut pasang.

Pembongkaran sarang dilakukan setelah masa inkubasi untuk mengeluarkan sisa penetasan dan telur yang tidak menetas. Pengamatan luar dilakukan pada telur yang gagal menetas, diperoleh hasil cangkang telur menyusut, bentuk cangkang tidak beraturan, warna cangkang keruh atau kekuningan, dan telur yang rusak (Gambar 2).

Total telur penyu lekang yang dipindahkan ke sarang semi alami BSTF adalah 4495 butir. Sebanyak 3392 butir telur berhasil menetas dan 1103 butir telur gagal menetas. Pada Bulan April total telur yang diinkubasi adalah 560, kemudian meningkat pada bulan berikutnya yaitu 1490 . Puncak bertelur penyu lekang pada periode tahun 2018 terjadi pada bulan Juni dengan total telur 2302 butir. Jumlah telur menurun pada akhir masa bertelur dibulan Juli menjadi 143 butir telur penyu lekang. Rata-rata jumlah telur adalah 102 butir per sarang. Jumlah tersebut lebih banyak jika dibandingkan jumlah telur penyu lekang di Costa Rica yaitu 89.8 butir per sarang (O’Brien, 2018).

Bézy et al., (2015) dan Sumarmin dkk. (2012) menyebutkan keberhasilan penetasan dipengaruhi interaksi antara faktor biotik dan abiotik, faktor biotik adalah predator dan adanya cemaran mikroba pada sarang, sedangkan faktor abiotik adalah karakter fisik dari substrat sarang atau pasir serta suhu dan kelembaban. Ruthig dan Gramera (2019) berpendapat bahwa predator penyu yaitu hewan dan manusia yang mengambil telur dari sarang alami untuk dikonsumsi sedangkan menurut Triantoro (2008) predator antara lain anjing, babi, dan kepiting yang memakan telur dan tukik ketika baru menetas.

Faktor lain yang dapat menurunkan penetasan telur penyu adalah adanya cemaran mikroorganisme. Verweij dan Brandt (2007) menyebutkan bahwa jamur dan bakteri dapat masuk melalui pori-pori cangkang telur kemudian menginfeksi telur, mengakibatkan kematian embrio, dan menurunkan penetasan telur. Booth dan Dunstan (2018) menjelaskan bahwa cemaran mikroorganisme dapat menyebabkan penurunan kadar oksigen, naiknya karbondioksida, diikuti dengan naiknya suhu dalam sarang yang berakibat pada kematian dini embrio (Early Embryo Death Syndrome). Valverde et al., (2010) menjelaskan bahwa telur busuk dalam sarang dapat menjadi media pertumbuhan bakteri, sehingga oksigen menurun, suhu naik, dan dapat menginfeksi telur yang sehat. Hal tersebut mengakibatkan penurunan penetasan pada sarang dengan kepadatan tinggi.

Wicaksono dkk. (2017) menemukan adanya cemaran bakteri, jamur, coliform, Enterobacter, dan Salmonella-Shigella pada cangkang dan bagian dalam telur. Praja dkk. (2018) melakukan isolasi jamur pada cangkang telur penyu lekang yang gagal menetas di Pantai Boom Banyuwangi, dari hasil penelitian ditemukan jamur Fusarium sp. dan Aspergillus sp. yang diduga mengakibatkan penurunan penetasan telur penyu. Adanya mikroorganisme dalam sarang dapat berasal dari sisa cairan setelah proses penetasan telur penyu maupun kontaminasi dari pasir sarang. Maulany et al., (2017) berpendapat bahwa penting untuk memperhatikan sarang penetasan dan manajemen penetasan untuk mempertahankan atau meningkatkan penetasan. Cara yang dapat dilakukan untuk memperbaiki kualitas sarang penetasan adalah dengan mengganti pasir sarang secara berkala (Bézy et al., 2015).

Souza et al., (2018) berpendapat bahwa adanya logam seperti $\mathrm{Cu}$ pada pasir sarang berpengaruh terhadap keberhasilan penetasan penyu. Peneliti lain yang melakukan identifikasi kandungan logam menemukan adanya Mn 12.07 ppm dan $\mathrm{Fe}$ 149,20 ppm yang melebihi batas normal pada pasir sarang yang dikhawatirkan mengakibatkan bioakumulasi dan dapat menjadi penghambat penetasan telur penyu (Primasatya dkk., 2013). Kandungan logam akan semakin toksik seiring dengan menurunnya nilai $\mathrm{pH}$ (Rochyatun dan Rozak, 2007).

Pengukuran $\mathrm{pH}$ pada sarang semi alami di Pantai Boom dilakukan selama masa inkubasi telur, dari pengukuran diperoleh nilai $\mathrm{pH}$ pada sarang semi alami BSTF adalah 3.8 - 6.7 tergolong asam ke netral masih sesuai untuk 
penetasan telur penyu. Penelitian sebelumnya di Pantai Boom Banyuwangi oleh Samosir dkk. (2018) menunjukkan bahwa $\mathrm{pH}$ netral lebih cocok untuk penetasan telur penyu dibandingkan pH asam, dengan persentase keberhasilan $80 \%$. Sejalan dengan pendapat Putu dan Warpala (2018) bahwa sarang penyu lekang mempunyai $\mathrm{pH}$ 7,73. Penurunan nilai $\mathrm{pH}$ dapat menyebabkan toksisitas logam berat yang ada di pasir atau pada telur makin besar, selain itu $\mathrm{pH}$ dapat mempengaruhi akumulasi logam berat dalam tubuh penyu (Jakimska et al., 2011).

Neeman et al., (2015) menyebutkan suhu juga mempengaruhi penetasan telur penyu. Pengukuran suhu pada sarang semi alami BSTF antara $29^{\circ} \mathrm{C}-32^{\circ} \mathrm{C}$ tidak jauh berbeda dengan pendapat Limpus (2009) mengenai suhu sarang yang cocok untuk penetasan telur penyu yaitu $25^{\circ} \mathrm{C}-33^{\circ} \mathrm{C}$, sementara Laloë et al., (2017) berpendapat suhu terendah dan tertinggi yang memberikan persentase penetasan yang baik adalah $28.5^{\circ} \mathrm{C}$ dan $32.2^{\circ} \mathrm{C}$. Suhu sarang dibawah $34^{\circ} \mathrm{C}$ menunjukkan persentase penetasan lebih baik dibandingkan suhu sarang diatas $34^{\circ} \mathrm{C}$ ( $\mathrm{Sim}$ et al., 2015). Suhu sarang yang melebihi $34^{\circ} \mathrm{C}$ selama 3 hari berturut-turut pada akhir masa inkubasi dapat menurunkan persentase kemunculan tukik, hal ini disebabkan oleh gangguan perkembangan sistem gerak tukik sehingga kebugaran tukik menurun dan tidak bisa mencapai permukaan sarang (Maulany et al., 2012).

Suhu sarang juga mempengaruhi lama masa inkubasi, lama masa inkubasi pada sarang semi alami BSTF antara 46 - 54 hari. Retnowati dkk. (2016) menyebutkan pada suhu sarang yang tinggi masa inkubasi telur penyu menjadi lebih cepat dan pada suhu yang rendah masa inkubasi menjadi lebih panjang. Telur penyu lekang yang diberi perlakuan suhu $30^{\circ} \mathrm{C}-33^{\circ} \mathrm{C}$ menetas pada hari ke-50 dan pada perlakuan suhu $26^{\circ} \mathrm{C}-27^{\circ} \mathrm{C}$ telur menetas pada hari ke-71 (Dima dkk., 2015). Menurut Sukamto dkk. (2016) penetasan penyu hijau pada sarang semi alami di Kawasan Konservasi Pantai Pangumbahan antara 46 - 60 hari.

Kelembaban di sarang semi alami BSTF antara 67\% - 80\%. Laloë et al., (2017) menyebutkan bahwa telur penyu sensitif terhadap lingkungan yang kering, namun pada kelembaban yang tinggi rawan terjadi pertumbuhan jamur pada cangkang telur. Kelembaban yang tinggi dapat disebabkan oleh tingginya kadar air dalam sarang. Air dalam sarang dapat berasal dari air hujan atau genangan air saat laut pasang (Pike et al., 2015). Hill et al., (2015); Nugroho dkk. (2017) berpendapat bahwa adanya naungan pada sarang semi alami dapat memberikan kestabilan kelembaban sarang, karena air hujan tidak langsung jatuh ke sarang.

Faktor lain yang juga berpengaruh adalah penanganan telur, penanganan yang kurang hatihati saat memindahkan telur dari sarang alami ke sarang semi alami juga dapat mempengaruhi penetasan (Ningsih dan Umroh, 2017), selain itu sebagian telur yang gagal menetas juga dapat disebabkan oleh telur yang infertil atau tidak terbuahi. O'Brien (2018) menyebutkan sekitar $12 \%$ dari total telur penyu lekang di Costa Rica merupakan telur infertil.

\section{KESIMPULAN}

Berdasarkan nilai persentase penetasan telur penyu lekang pada sarang semi alami BSTF periode tahun 2018 sebesar $75 \%$, dengan total telur 4495 butir, 3392 butir menetas, dan 1103 butir tidak menetas.

\section{UCAPAN TERIMA KASIH}

Peneliti mengucapkan terimakasih kepada Banyuwangi Sea Turtle Foundation (BSTF) dan Fakultas Kedokteran Hewan Universitas Airlangga PSDKU Banyuwangi atas izin yang telah diberikan untuk melakukan penelitian.

\section{DAFTAR PUSTAKA}

Behera, S.K., Mohanta, R.K., Kar, C., Mishra, S.S. 2014. Impacts of the Super Cyclone Philine on Sea Turtle Nesting Habitats at the Rushikulya Rookery, Ganjam Coast, India. Poult. Fisheries Wildl. Sci.2, 114: 1-5. 
Bézy, V.S., Valverde, R.A., Plante, C.J. 2015. Olive Ridley Sea Turtle Hatching Success as a Function of the Microbial Abundance in Nest Sand at Ostional, Costa Rica. PloS one, 10(2), e0118579.

Booth, D.T., Dunstan, A. 2018. A Preliminary Investigation into the Early Embryo Death Syndrome (EEDS) at The World's Largest Green Turtle Rookery. PloS one, 13(4), e0195462.

Brost, B., Witherington, B., Meylan, A., Leone, E., Ehrhart, L., Bagley, D. 2015. Sea Turtle Hatchling Production from Florida (USA) Beaches, 2002-2012, with Recommendations for Analyzing Hatching Success. Endangered Species Res., 27(1), 53-68.

Dermawan, A., Nuitja, I.N.S., Soedharma., Halim, M.H., Kusrini, M.D., Lubis, S.B., Alhanif, R., Khazali, M., Murdiah, M., Wahjuhardini, P.L., Setiabudiningsih., Mashar, A. 2009. Pedoman Teknis Pengelolaan Konservasi Penyu. Direktorat Konservasi dan Taman Nasional Laut. Direktorat Konservasi dan Taman Nasional Laut, Direktorat Jenderal Kelautan, Pesisir dan Pulau-Pulau Kecil, Departemen Kelautan dan Perikanan RI. Jakarta. Hal 123.

Dima, A.O.M., Solihin, D.D., Manalu, W., Boediono, A. 2015. Profil Ekspresi Gen Determinasi Seks, Bioreproduksi, Fenotipe, dan Performa Lokomotori Penyu Lekang (Lepidochelys olivacea) yang Dïnduksi Suhu Inkubasi Berbeda. J. Ilmu Teknol. Kelautan Trop., 7(1), 143-155.

Hill, J.E., Paladino, F.V., Spotila, J.R., Tomillo, P.S. 2015. Shading and Watering as a Tool to Mitigate the Impacts of Climate Change in Sea Turtle Nests. PloS one, 10(6), e0129528.

Jakimska, A., Konieczka, P., Skóra, K., Namieśnik, J. 2011. Bioaccumulation of Metals in Tissue Marine Animals, Part I: the Role and Impact of Heavy Metals on
Organism. J. Environ. Studies, 20(5), 11171125.

Karnan. 2008. Penyu Hijau: Status dan konservasinya. Jurnal Pijar MIPA, 3(1), 3946.

Laloë, J.O., Cozens, J., Renom, B., Taxonera, A., Hays, G.C. 2017. Climate Change and Temperature-Linked Hatchling Mortality at a Globally Important Sea Turtle Nesting Site. Glob. Change Biol., 23(11), 4922-4931.

Limpus, C.J. 2009. A Biological Review of Australian Marine Turtle Species. 6. Leatherback Turtle, Dermochelys coriacea. (Vandelli). the State of Queensland. Environmental Protection Agency. pp28.

Listiani, F., Mahardika, H.R., Prayogo, N.A. 2015. Pengaruh Karakteristik Pasir dan Letak Sarang Terhadap Penetasan Telur Penyu Hijau (Chelonian mydas) di Pantai Goa Cemara, Bantul. Omni-Akuatika, 14(20), 6368.

Maulany, R.I., Booth, D.T., Baxter, G.S. 2012. the Effect of Incubation Temperature on Hatchling Quality in the Olive Ridley Turtles From Alas Purwo National Park, East Java, Indonesia. Marine Biol., 159(12), 2651-2661.

Maulany, R.I., Baxter, G.S., Booth, D.T., Spencer, R.J. 2017. Population Viability Analysis (PVA) for Ridley Turtles (Lepidochelys olivacea) Nesting in Alas Purwo National Park, Indonesia. Malay. Forester, 80(2), 198-217.

Mortimer, J.A., Donnelly, M. 2008. Eretmochelys imbricata. In: IUCN 2010. IUCN Red List of Threatened Species. Version 2010.1. http://www.iucnredlist.org/details/8005/0 (Accessed on 14 January 2018).

Neeman, N., Robinson, N.J., Paladino, F.V., Spotila, J.R., O'Connor, M.P. 2015. Phenology Shifts in Leatherback Turtle 
(Dermochelys coriacea) due to Changes in Sea Surface Temperature. J. Exp. Marine Biol. Ecol., 462, 113-120.

Ningsih, F., Umroh, U. 2017. Perbandingan Keberhasilan Penetasan Telur Penyu Sisik (Eretmochelys imbricata) di Penangkaran Penyu Pantai Tongaci dan UPT Penangkaran Penyu Guntung. Akuatik: Jurnal Sumberdaya Perairan, 11(1), 77-81

Nugroho, Aditya, D., Redjeki, S., Taufiq, N. 2017. Studi Karakteristik Sarang Semi Alami Terhadap Daya Tetas Telur Penyu Hijau (Chelonia mydas) di Pantai Paloh Kalimantan Barat. Prosiding Seminar Nasional HasilHasil Penelitian Perikanan dan Kelautan keVI Fakultas Perikanan dan Ilmu KelautanPusat Kajian Mitigasi Bencana dan Rehabilitasi Pesisir. Universitas Diponegoro 422-433.

O'Brien, N. 2018. A Correlation Study of the Nest Incubation Period and Hatchling Development and Success Rate for Olive Ridley Sea Turtles (Lepidocheyls olivacea) Turtle Conservation: Playa Junquillal, Costa Rica. Honors Research Projects. 762, 1-23.

O’Connor, J.M., Limpus, C.J., Hofmeister, K.M., Allen, B.L., Burnett, S.E. 2017. Anti-Predator Meshing May Provide Greater Protection for Sea Turtle Nests than Predator Removal. PloS one, 12(2), e0171831.

Pike, D.A., Roznik, E.A., Bell, I. 2015. Nest Inundation from Sea-Level Rise Threatens Sea Turtle Population Viability. Royal Society Open Sci., 2(7), e150127.

Praja, R.N., Yudhana, A., Haditanojo, W. 2018. Isolasi dan Identifikasi Jamur pada Cangkang Telur Penyu Lekang (Lepidochelys olivacea) Gagal Menetas di Pantai Boom Banyuwangi. J. Med. Vet., 1(2), 11-15.

Primasatya, E., Elfidasari, D., Sugoro, I. 2013. Identifikasi Kandungan Logam Berat Pada
Pasir Sarang Penyu Hijau (Chelonia mydas). Prosiding Seminar Nasional Matematika, Sains, dan Teknologi 4: B.143-B150.

Putu, M.O.D., Warpala, I.W.S. 2018. Karakteristik Biofisikokimia Habitat Peneluran Penyu Lekang (Lepidochelys olivacea) di Situs Konservasi Penyu Pantai Penimbangan Kota Singaraja. J. Pend. Biol. Undiksha, 7(2).

Retnowati, Yudaningtyas, E., Rahmadwati, Muslimah, A., Hasan, I., Muttaqin, M.A., Azman, F.Y. 2016. Pengendalian Suhu dan Kelembaban pada Proses Penetasan Telur Penyu Menggunakan Kontrol Logika Fuzzy. Fakultas Teknik. Universitas Brawijaya.

Rochyatun, E., Rozak, A. 2007. Pemantauan Kadar Logam Berat dalam Sedimen di Perairan Teluk Jakarta. J. Makara Sains, 11(1), 28-36.

Rofiah, A., Hartati, R., Wibowo, E. 2012. Pengaruh Naungan Sarang Terhadap Presentase Penetasan Telur Penyu Lekang (Lepidochelys olivacea) di Pantai Samas Bantul, Yogyakarta. J. Marine Res., 1(2), 103-108.

Ruthig, G.R., Gramera, A.E. 2019. Aggregations of Olive Ridley Sea Turtle (Lepidochelys olivacea Eschholtz, 1829) Nests is Associated with Increased Human Predation during an Arribada event. Herpetolo. Notes, 12, 1-7.

Samosir, S.H., Hernawati, T., Yudhana, A. 2018. Perbedaan Sarang Alami dengan Semi Alami Mempengaruhi Masa Inkubasi dan Keberhasilan Menetas Telur Penyu Lekang (Lepidochelys olivacea) Pantai Boom Banyuwangi. J. Med. Vet., 1(2), 1-5.

Sarahaizad, M.S., Shahrul A,M.S., Mansor, Y. 2012. Nest Site Selection and Digging Attempts of Green Turtles (Chelonia mydas, Fam. Cheloniidae) at Pantai Kerachut and 
Telok Kampi, Penang Island, Peninsular Malaysia. Malay. App. Biol. J., 41(2), 31-39.

Sim, E.L., Booth, D.T., Limpus, C.J. 2015. Incubation Temperature, Morphology and Performance in Loggerhead (Caretta Caretta) Turtle Hatchlings from Mon Repos, Queensland, Australia. Biol. Open., 4, 685692.

Souza, N.L.N., Carneiro, M.T.W.D., Pimentel, E.F., Frossard, A., Freire, J.B., Endringer, D.C., Júnior, P.D.F. 2018. Trace Elements Influence the Hatching Success and Emergence of Caretta caretta and Chelonia mydas. J. Trace Elements Med. Biol.

Sukamto, Muryanto, T., Sarbini, R. 2016. Teknik Penetasan Telur Penyu Hijau (Chelonia mydas) di Kawasan Konservasi, Pantai Pangumbahan, Kabupaten Sukabumi, Jawa Barat. Buletin Teknik Litkayasa (BTL) Sumber Daya Dan Penangkapan, 14(1), 2932.

Sumarmin, R., Helendra, H., Putra, A.E. 2012. Daya Tetas Telur Penyu Sisik (Eretmochelys imbricate L.) pada Kedalaman Sarang dan Strata Tumpukan Telur Berbeda. Eksakta, 1(8), 70-77.
Triantoro, Richard, G.N. 2008. Karakteristik Biologi Penyu Belimbing (Dermochelys coriacea Vandelli) di Suaka Margasatwa Jamursba Medi, Papua Barat. Info Hutan 5(2), 189-198.

Valverde, R.A., Wingard, S., Gómez, F., Tordoir, M.T., Orrego, C.M. 2010. Field Lethal Incubation Temperature of Olive Ridley Sea Turtle Lepidochelys olivacea Embryos at A Mass Nesting Rookery. Endangered Species Res., 12(1), 77-86.

Verweij, P.E., Brandt, M.E. 2007. Aspergillus Fusarium, and Other Opportunitistic Moniliaceous Fungi. In : Murray et al. (eds). Manual of Clinical Microbiology. Ch. 121. 9th ed. ASM Press. Washington DC. 18021838.

Wicaksono, M.A., Nurhasanah, F., Elfidasari, D. 2017. Cemaran Mikroba Pada Telur Penyu Sisik (Eretmochelys imbricata) di Pulau Kelapa Dua, Taman Nasional Laut Kepulauan Seribu, DKI Jakarta. J. Al-Azhar Indon. Seri Sains Tek., 4(2), 83-90.

Yustina, Suwondo, Arnentis, Hendri, Y. 2004. Analisis Distribusi Sarang Penyu Hijau Chelonian mydas di Pulau Jemur Riau. J. Biogen., 1(1), 31-36. 